Article

\title{
Assessing the Potential of Upcoming Satellite Altimeter Missions in Operational Flood Forecasting Systems
}

\author{
Aline Falck ${ }^{1, *(\mathbb{D})}$, Javier Tomasella ${ }^{1}$ (D) and Fabrice Papa ${ }^{2,3}(\mathbb{D}$ \\ 1 Centro Nacional de Monitoramento e Alerta de Desastres Naturais (CEMADEN), \\ São José dos Campos 12.247-016, SP, Brazil; javier.tomasella@cemaden.gov.br \\ 2 Laboratoire d'Etudes en Géophysique et Océanographie Spatiales (LEGOS), Université de Toulouse, IRD, \\ CNES, CNRS, UPS-14 Avenue Edouard Belin, 31400 Toulouse, France; fabrice.papa@ird.fr \\ 3 Instituto de Geociências, Universidade de Brasília (UnB), Brasília 70.910-900, DF, Brazil \\ * Correspondence: aline.falck@cemaden.gov.br
}

check for updates

Citation: Falck, A.; Tomasella, J.;

Papa, F. Assessing the Potential of Upcoming Satellite Altimeter Missions in Operational Flood Forecasting Systems. Remote Sens. 2021, 13, 4459. https://doi.org/ $10.3390 / \mathrm{rs} 13214459$

Academic Editor: Guy J.-P. Schumann

Received: 10 September 2021

Accepted: 2 November 2021

Published: 6 November 2021

Publisher's Note: MDPI stays neutral with regard to jurisdictional claims in published maps and institutional affiliations.

Copyright: (c) 2021 by the authors. Licensee MDPI, Basel, Switzerland. This article is an open access article distributed under the terms and conditions of the Creative Commons Attribution (CC BY) license (https:// creativecommons.org/licenses/by/ $4.0 /)$.

\begin{abstract}
This study investigates the potential of observations with improved frequency and latency time of upcoming altimetry missions on the accuracy of flood forecasting and early warnings. To achieve this, we assessed the skill of the forecasts of a distributed hydrological model by assimilating different historical discharge time frequencies and latencies in a framework that mimics an operational forecast system, using the European Ensemble Forecasting system as the forcing. Numerical experiments were performed in 22 sub-basins of the Tocantins-Araguaia Basin. Forecast skills were evaluated in terms of the Relative Operational Characteristics (ROC) as a function of the drainage area and the forecasts' lead time. The results showed that increasing the frequency of data collection and reducing the latency time (especially $1 \mathrm{~d}$ update and low latency) had a significant impact on steep headwater sub-basins, where floods are usually more destructive. In larger basins, although the increased frequency of data collection improved the accuracy of the forecasts, the potential benefits were limited to the earlier lead times.
\end{abstract}

Keywords: satellite mission; update; latency; initial condition; hydrological model; floods

\section{Introduction}

Early warning and emergency response to destructive river floods depend on accurate and timely forecasts. However, in spite of recent advances, hydrological forecasts are still performing poorly in many regions worldwide. This is due to the fact that hydrological forecasts are impacted by several sources of uncertainty such as input forcing (numerical weather prediction outputs), hydrological model parameters and structures, and the model initial conditions (state variables), related not only to model errors, but also to interpolated meteorological data, particularly in areas of poor network coverage [1-3]. In this context, the use of assimilation techniques is an important component of hydrologic forecasting systems [4-7]; in particular, the assimilation of discharge data provides a way to improve the forecasts by reducing errors on the initial conditions and/or state parameters. Despite the clear advantage of data assimilation in flood forecast systems, they are often limited by the need for real-time information with an adequate spatial distribution, especially in the case of distributed hydrological models.

Until recently, the hydrological network in Brazil favored the monitoring of medium to large-sized watersheds with hydroelectric potential and large dam infrastructures [8]. Although the existent network has been upgraded in recent years, most of the gauging stations are still manually operated and do not provide real-time data. Most of the existent long-term records hydrological and rainfall data, especially in remote areas such as the Amazon, are collected by the Brazilian water agency (ANA), twice a day in manual logs, for later processing. 
Since the 1970s, the migration of the rural population to urban areas in many regions of Brazil has resulted in the occupation of riparian zones, usually with precarious housing, and often exposed to flooding and landslides [9]. From 2011, with the creation of the National Centre for Monitoring and Early Warning of Natural Disasters (CEMADEN), a new network of automatic weather stations, with data transmission based on the mobile network, was deployed mostly in headwater catchments in highly populated areas of Brazil. However, large basins (mostly located in the north of Brazil) still have poor data coverage, especially in terms of real-time data. The lack of real-time data coverage is an obstacle for implementing mitigation actions, especially for isolated communities affected by periodical floods.

Consequently, the use of other monitoring techniques, such as advanced remote sensing observations, provides an opportunity to improve hydrologic forecasting simulations [10-14] and, consequently, flood preparedness. In particular, satellite altimetry provides accurate measurements of water level variations in rivers and floodplains $[15,16]$, which can be valuable for hydrologic simulations $[17,18]$, especially when they can be converted into discharge estimations $[19,20]$.

Nevertheless, a major drawback in the use of observations from past and current nadir altimetric missions for operational applications is the temporal sampling rate at a given location [21]. The repeat cycle ranges from $10 \mathrm{~d}$ (for Topex-Poseidon, Jason-2/3/CS) to $35 \mathrm{~d}$ (for ERS-1/2, ENVISAT, SARAL-AltiKa), while recently launched missions (Sentinel $3 \mathrm{~A} / \mathrm{B})$ are on a $27 \mathrm{~d}$ repeat cycle. Such time sampling intervals cannot compete with observations made daily or twice daily by in situ gauges, a frequency required to study fast local hydrological processes and to evaluate flood risk. In a recent study, Sikder et al. [22] suggested that observations with a frequency of 1-3 d on a Jason-like orbit could be sufficient to characterize most of the global spatial distributions of the magnitude and duration of flood events.

Data latency (i.e., the time or delay that data take to be available) is also a crucial parameter for operational applications in hydrology, and recent studies showed that short data latencies, on the order of a few hours to a few days, are critical for timely forecasts. For instance, Allen et al. [23] demonstrated that, globally, flood waves moving at their maximum speed reach a city or a dam in a median time of $4 \mathrm{~d}$ and $3 \mathrm{~d}$, respectively. No altimetry mission currently offers the capability to provide data with adequate short latencies.

Originally, altimetry missions were built with the prime objective to observe the ocean surface topography, and up to now, past and current mission requirements have not considered continental hydrology needs as an objective.

However, the upcoming generation of new satellite altimeters is designed with the primary goals to also study continental hydrology and to observe how rivers and continental water bodies change over time. For instance, the Surface Water and Ocean Topography (SWOT) mission [24] will be able to provide water stage and discharge measurements on a global scale every $21 \mathrm{~d}$ (thanks to its wide-swath technique, this revisit time will be reduced to $\sim 11 \mathrm{~d}$ in tropical regions) with a possible latency time of $3 \mathrm{~d}$ (in the best-case scenario) [21].

Additionally, in order to resolve the coarse time sampling issue of altimetry missions, The SMall Altimetry Satellite for Hydrology (SMASH) constellation [25] is currently under study by the scientific community with the support of the French Space Agency (CNES). It is designed with the objectives to provide observations of daily water levels using a constellation of 10 satellites on a similar orbit as the Jason missions, along with a short latency time (from few hours to one day). Therefore, even if these upcoming missions are not entirely designed to provide real-time data for operational purposes, they might still offer great opportunities in flood forecasting applications. Consequently, in this paper, we explore the potential application of this new and upcoming generation of altimetry missions, such as SWOT and SMASH, for improving the skill of flood forecast in remote regions with poor real-time water level coverage. To achieve this, we analyzed how the forecast skill of a distributed hydrological model is affected by the availability of discharge 
observations at different time frequencies and latencies. The experiment was performed in the Tocantins-Araguaia Basin, located in Northern Brazil, a region with very scarce spatial data, particularly in real-time.

Section 2 presents the study area. Section 3 exhibits the hydrological model and dataset. Section 4 shows the methodology. Section 5 shows the results and discussions. Finally, Section 6 presents the summary and conclusions.

\section{Study Area}

The Tocantins-Araguaia River Basin covers more than $760,000 \mathrm{~km}^{2}$ from its headwaters in Central Brazil to the Hydropower Plant (HPP) Tucuruí (Figure 1) near its outlet. The Tocantins River is the easternmost large tributary of the Amazon Basin and hosts Bananal Island (considered as the biggest river island of the world) located on the Araguaia River [26].

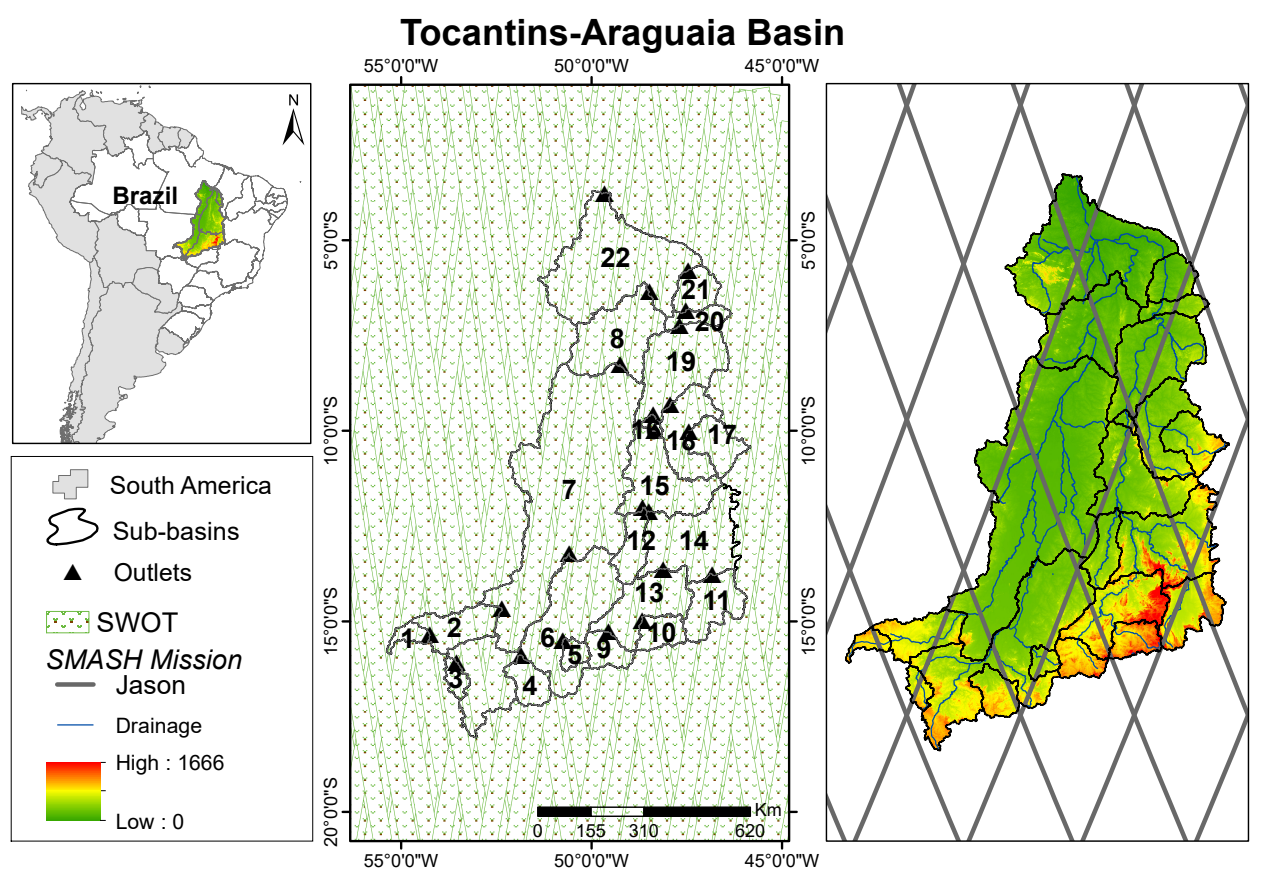

Figure 1. (Left) Location of Tocantins-Araguaia Basin with its topography; (middle) sub-basin catchments (see Table 1 for details) and their outlets along with the ground-tracks of the SWOT mission; (right) drainage network along with the ground-tracks of the SMASH mission (equivalent here to Jason ground-tracks).

The basin has well-defined dry and rainy seasons. The Tocantins-Araguaia Basin is subject to different meteorological systems. The southern part of the basin, where most of its headwaters are located, is dominated by the South Atlantic Convergence Zone (SACZ) and by a zone of convergence of humidity. The climate at the outlet further north is dominated by the Inter-Tropical Convergence Zone (ITCZ) [27].

The vegetation cover is predominantly Brazilian savanna (Cerrado) in the upper part of the basin and Amazon Rainforest in the lower Tocantins, downstream of the basin. Because of its great natural resources, characterized by large availability of water, the basin has many areas of environmental preservation and also a very large hydroelectric potential. Furthermore, these rivers are of major importance for transportation and agricultural commodities.

The Tocantins-Araguaia River Basin is characterized by a smooth topography for most of its drainage areas, presenting altitudes above $1000 \mathrm{~m}$ in its headwaters. The climate regimes for Brazil were classified by Alvares et al. [28], making the Tocantins-Araguaia Basin predominantly tropical with dry winter $(\mathrm{Aw})$ and tropical monsoon (Am). 
Table 1. Tocantins-Araguaia Basin characteristics and hydrological model calibration (2000-2010) and validation (2011-2014) periods in terms of NSE and NSE $E_{\log }$.

\begin{tabular}{|c|c|c|c|c|c|c|c|c|}
\hline \multirow{2}{*}{ Sub-Basin } & \multirow{2}{*}{ Station } & \multirow{2}{*}{ River } & \multirow{2}{*}{ Classf. } & \multirow{2}{*}{ Area $\left(\mathrm{km}^{2}\right)$} & \multicolumn{2}{|c|}{ Calibration } & \multicolumn{2}{|c|}{ Validation } \\
\hline & & & & & $N S E$ & $N S E_{\log }$ & NSE & $N S E_{\log }$ \\
\hline SB01 & Rio das Mortes & Mortes & Small & 5230 & 0.711 & 0.740 & - & - \\
\hline SB02 & Xavantina & Mortes & Medium & 25,300 & 0.821 & 0.842 & 0.859 & 0.889 \\
\hline SB03 & Tesouro & Garças & Small & 5280 & 0.584 & 0.682 & 0.610 & 0.657 \\
\hline SB04 & Peres & Caiapó & Small & 12,000 & 0.695 & 0.795 & 0.703 & 0.853 \\
\hline SB05 & Travessão & Vermelho & Small & 5310 & 0.665 & 0.816 & 0.588 & 0.786 \\
\hline SB06 & Luiz Alves & Araguaia & Medium & 117,000 & 0.842 & 0.900 & 0.878 & 0.897 \\
\hline SB07 & Conceição do Araguaia & Araguaia & Large & 332,000 & 0.853 & 0.890 & 0.882 & 0.906 \\
\hline SB08 & Xambioá & Araguaia & Large & 377,000 & 0.897 & 0.901 & 0.944 & 0.932 \\
\hline SB09 & Ceres & Almas & Small & 10,600 & 0.745 & 0.803 & 0.707 & 0.824 \\
\hline SB10 & Ponte Quebra Linha & Maranhão & Small & 11,200 & 0.631 & 0.792 & 0.581 & 0.746 \\
\hline SB11 & Nova Roma (Faz.Sucuri) & Paraná & Small & 22,600 & 0.743 & 0.767 & 0.769 & 0.809 \\
\hline SB12 & Jacinto & Sta Tereza & Small & 13,900 & 0.734 & 0.793 & 0.752 & 0.792 \\
\hline SB13 & HPP Serra da Mesa & Tocantins & Medium & 51,233 & 0.798 & 0.747 & 0.773 & 0.791 \\
\hline SB14 & HPP Peixe Angical & Tocantins & Medium & 125,884 & 0.614 & 0.598 & 0.756 & 0.737 \\
\hline SB15 & HPP Lajeado & Tocantins & Medium & 183,718 & 0.843 & 0.865 & 0.884 & 0.900 \\
\hline SB16 & Miracema do Tocantins & Tocantins & Medium & 185,000 & 0.872 & 0.836 & 0.812 & 0.829 \\
\hline SB17 & Jatobá (Faz. Boa Nova) & Sono & Small & 16,900 & 0.590 & 0.660 & 0.665 & 0.774 \\
\hline SB18 & Porto Real & Sono & Medium & 44,100 & 0.795 & 0.864 & 0.850 & 0.892 \\
\hline SB19 & Carolina & Tocantins & Large & 275,000 & 0.868 & 0.946 & - & - \\
\hline SB20 & HPP Estreito & Tocantins & Large & 285,491 & 0.942 & 0.922 & 0.952 & 0.949 \\
\hline SB21 & Descarreto & Tocantins & Large & 297,000 & 0.957 & 0.953 & 0.992 & 0.992 \\
\hline SB22 & HPP Tucuruí & Tocantins & Large & 764,000 & 0.946 & 0.953 & 0.965 & 0.968 \\
\hline
\end{tabular}

\section{Hydrological Model and Datasets}

\subsection{Hydrological Model}

The Distributed Hydrological Model (MHD) is a model developed by the Brazilian National Institute for Space Research (INPE). This model has been widely used in climate change and land use/land cover change impact studies [29-33], for hydrological monitoring [34,35], probabilistic flood forecasting [36-38], and quantifying economic indicators of droughts [30].

The hydrological model MHD-INPE is a regular grid-based model, which uses a combination of the probabilistic approach of the Xinanjiang model and the TopModel formulation to simulate runoff generation. The application of the MHD-INPE model requires information related to river drainage networks, such as flow direction, flow accumulation areas, basin delineation, and the length and slope of river reaches in every grid cell, which are derived from a digital elevation model. In this study, the digital elevation model was derived from the Shuttle Radar Topography Mission (SRTM) [39], with a spatial resolution of $90 \mathrm{~m}$, and was upscaled to the hydrological model resolution used in this study $\left(0.25^{\circ}\right)$.

The characteristics of each grid cell hydrological response units, of the MHD-INPE model, result from the combination of the soil type and land use data, derived as follows:

- Using the HAND model [40], soil environments were classified as suggested by Cuartas et al. [41], subdividing the basins into four different environments: valley, footslope, upslope, and plateau. The threshold for different HAND environments was determined by visual analysis, with comparative support of the basin soil map Santos et al. [42] and by relating soil toposequences to the HAND environments [41];

- Annual Land Use and Land Cover change (LULC) maps used in this study were provided by the MapBiomas Project Collection 5 [43] for the period 2000-2014. Vegetation types within the basin include forest formation, savanna formation, mangrove, forest plantation, grassland, pasture, agricultural mosaic, and silviculture. Consequently, the hydrological response units were updated yearly in accordance with the LULC maps, as described by Rodriguez and Tomasella [31].

For the implementation of the hydrological model, the Tocantins-Araguaia River Basin was subdivided in 22 sub-basins (Figure 1) according to the streamflow stations listed 
in Table 1. The MHD-INPE model was calibrated from January 2000 through December 2010, disregarding the first two years required for model spin-up, using the shuffled complex evolution algorithm [44]. The objective function used for calibration was a combination of the Nash-Sutcliffe streamflow efficiency parameter-NSE, and the NashSutcliffe efficiency parameter of the logarithm of streamflow-NSE $E_{\log }$. The calibration was conducted for each sub-basin at a time, beginning at headwater sub-basins and following downstream to higher-order sub-basins. Model parameters were calibrated and validated using daily precipitation satellite data of MERGE-CPTEC and daily observations of meteorological data interpolated over the basin. The hydrological model was validated for the period January 2011-December 2014, as exhibited in Table 1.

\subsection{Hydrometeorological Data}

The hydrological and meteorological data were the same as the ones described in Falck et al. [38]. They included the hydrometeorological daily data from 41 meteorological stations (air temperature, dew point temperature, atmospheric pressure, incident global radiation, and wind speed) from the Brazilian National Meteorological Service (INMET) and 22 streamflow stations from ANA.

\subsection{Satellite Rainfall Estimates}

MERGE is a product of satellite rainfall estimates, in which observed precipitation data are combined with satellite-derived precipitation estimates. The technique was developed by Rozante et al. [45] and used data from the Tropical Rainfall Measuring Mission (TRMM), currently discontinued and replaced by Global Precipitation Measurement-Integrated Multi-satellitE Retrievals for GPM (GPM-IMERG). This technique aims to minimize uncertainties in precipitation data associated with interpolations over regions with low rain gauges density. In the latest version, a single adaptation was made to the algorithm to remove a considerable number of points near each observation station to preserve that station radius of action.

According to Rozante et al. [46], the observation data used for the correction of satellite data (over South America) were from the Global Telecommunications System (GTS), INMET, the Paraná Meteorological System (SIMEPAR), Companhia Energética de Minas Gerais (CEMIG), the Agronomic Institute of Campinas (IAC), and others. For the construction of the daily accumulated rainfall estimates, the accumulated precipitation between the $12 \mathrm{~h}$ of the Greenwich Meridian (GMT) of the previous day and the 12 GMT of the current day [47] was used. Quality controls were also carried out to identify and mark spurious data to determine whether to accept or reject the data. Further details can be found in Rozante et al. [48].

The MERGE product is available with a daily temporal resolution and a spatial resolution of $0.1^{\circ}$. For the period 2000-2014 (15 y), the data were resampled at a spatial resolution of $0.25^{\circ}$ to match the hydrological model grid. Because the MERGE product is also available in real-time, which makes it more suitable for the purpose of this study, the hydrological model calibration, validation, and initialization were based on the MERGE rainfall estimates rather than interpolated rainfall from the conventional manual network of the Brazilian Water Agency.

\subsection{Daily Weather Forecast}

The ECMWF EPS is a global numerical weather prediction system integrating The Observing System Research and Predictability Experiment (THORPEX) Interactive Grand Global Ensemble (TIGGE) dataset [49,50]. As described in Falck et al. [38], the ECMWF EPS uses an ensemble composed of 50 forecasts generated from perturbed initial conditions and one control forecast from an unperturbed initial condition. The last upgrade of the model for operational implementation was made on 6 June 2020, and details are available in the Integrated Forecasting System (IFS) documentation (CY47r1) [51]. The system runs twice a day (00 and $12 \mathrm{UTC}$ ) with a forecast lead time of $0-15 \mathrm{~d}$ and uses a variable resolution 
approach during the forecast period (VAREPS) [52]: a finer resolution grid in the early forecast range Tco639L91 $(0-10 \mathrm{~d}) \sim 16 \mathrm{~km}$ and a coarser one in the remaining forecast period Tco319L91 (10-15 d) 32 km [51]. The data are retrieved using the Meteorological Archive and Retrieval System (MARS) where they are available in the horizontal resolution of $0.25^{\circ}$ for the first $10 \mathrm{~d}$ of forecast and $0.5^{\circ}$ after $10 \mathrm{~d}$. The MARS system uses a bilinear interpolation method to regrid the forecast fields to a new resolution of interest.

For this study, we used the spatial resolution of $0.25^{\circ}$ to match the MHD-INPE hydrological model resolution, with daily forecasts up to a $15 \mathrm{~d}$ lead time period. The forecasted variables are precipitation, wind speed at $10 \mathrm{~m}$, surface air pressure, air and dew point temperatures at $2 \mathrm{~m}$, and incident solar radiation, during the period from 2007 to 2014 over the Tocantins-Araguaia Basin. These variables, except precipitation, are used by the MHD-INPE model to estimate evaporation. Further details of the ECMWF setup in this experiment can be found in Falck et al. [38].

\section{Methodology}

\subsection{Hydrological Run Experiments}

Altimeter satellite information available as of today can provide at best the river water stage at fixed locations with a time frequency of $\sim 10 \mathrm{~d}$, with a latency time of $\sim 2 \mathrm{~d}$. Considering that future constellations of satellite altimeters might be able to provide data with a higher temporal resolution and shorter latency time, we explored the impacts on the quality of river forecasts in the Tocantins-Araguaia Basin for data collection intervals ranging from $1 \mathrm{~d}$ to $11 \mathrm{~d}$ and latency times ranging from $0 \mathrm{~d}$ to $3 \mathrm{~d}$. Although we cannot assess whether future altimeter missions will be capable of achieving the most demanding processing time intervals due to technological and logistic challenges, these sets of numerical experiments are useful for providing guidance to the satellite community about the potential gains in a flood forecasting system in a remote basin as a consequence of having more detailed information.

To evaluate the potential use of satellite altimetric data in a flood forecasting operational system, we organized the hydrological model to run 16 experiments using the ensemble forecasting system of ECMWF ( $15 \mathrm{~d}$ lead times and 51 members) considering different frequencies of updates and latencies that could be potentially available with upcoming satellite altimetry missions (such as the SWOT and SMASH missions).

Since current satellite altimeter estimations do not cover the whole historical period of the time frequency and the spatial resolution needed for this type of numerical experiment, we used past discharge observations as if they were derived from satellite altimeter observations (considering that each of the sub-basins has discharge rating curves). It might be argued that this assumption does not take into account the errors involved in discharge estimations due to the uncertainties in water level estimations of satellite altimeters. However, considering that river discharge measurements are affected by measurement errors and by the uncertainties in the fitting of the ratio curve, this simplification had minor impacts on the final results.

Therefore, to mimic an operational forecast system, we updated the hydrological model assuming that the real-time satellite stage data were being used to estimate rivers discharges in each of the sub-basins depicted in Figure 1. In other words, historical discharges were used to correct (assimilate) the simulated discharges of the hydrological model as if they were satellite estimated discharges.

The experiments used 1, 3, 7, and $11 \mathrm{~d}$ of updates and $0 \mathrm{~h}$ (no latency), $24 \mathrm{~h}, 48 \mathrm{~h}$, and $72 \mathrm{~h}$ of latency (a total of 16 experiments). We performed daily simulations between 2007 and 2014 (8 y).The effect of latency on the data availability was simulated in the model by updating observations using data corresponding to $0 \mathrm{~h}, 24 \mathrm{~h}, 48 \mathrm{~h}$, and $72 \mathrm{~h}$ before the start of the forecasts. For the SWOT mission, the revisit period was $21 \mathrm{~d}$. However, taking advantage of the swath data, the same scene would be revisited a few times during the $21 \mathrm{~d}$ orbit. On average, every point would be revisited every $11 \mathrm{~d}$ globally. An update every 11 
d was chosen according to Biancamaria et al. [24] and Papa et al. [20], which considered such a revisit time for this region.

Flood forecasts were performed using meteorological interpolated fields and satellite rainfall estimates to bring the hydrological model to the initial conditions. Then, the model was updated using observed discharges according to the experimental design (different time intervals and latency times). ECMWF forecasts were used as the input of the hydrological model (offline coupling). This approach is generally used in many operational flood forecast systems (for instance, Alfieri et al. [53]).

In this study, we applied the recursive update algorithm described by Wöhling et al. [54]. This technique was applied to reproduce the operational initial conditions of a forecast system and to assimilate the measured streamflow at the start of the streamflow forecast. The recursive update was successfully used by Tomasella et al. [37] and Falck et al. [38].

To analyze and interpret the results, the whole Tocantins-Araguaia Basin was divided into small, medium, and large sub-basins, based on the size of the drainage areas, arbitrarily chosen. As indicated in Table 1, small sub-basins included the headwaters with drainage areas smaller than $25,000 \mathrm{~km}^{2}$, medium sub-basins between $25,000 \mathrm{~km}^{2}$ and $200,000 \mathrm{~km}^{2}$, and large sub-basins having drainage areas greater than $200,000 \mathrm{~km}^{2}$.

\subsection{Performance Analysis}

The hydrological model performance was assessed by comparing the Nash-Sutcliffe objective function and the adjusted parameters, namely Nash-Sutcliffe Efficiency (NSE) and Logarithm Nash-Sutcliffe Efficiency $\left(N S E_{l o g}\right)$.

$$
N S E=1-\frac{\sum_{t=1}^{n}\left(Q S_{t}-Q O_{t}\right)^{2}}{\sum_{t=1}^{n}\left(Q O_{t}-\overline{Q O}\right)^{2}}
$$

and:

$$
N S E_{\log }=1-\frac{\sum_{t=1}^{n}\left(\log \left(Q S_{t}\right)-\log \left(Q O_{t}\right)\right)^{2}}{\sum_{t=1}^{n}\left(\log \left(Q O_{t}\right)-\overline{\log (Q O)}\right)^{2}}
$$

where $Q S_{t}$ and $Q O_{t}$ are the simulated and observed daily streamflow, $\log \left(Q S_{t}\right)$ and $\log \left(Q O_{t}\right)$ are the natural logarithm of the simulated and observed daily streamflow, $n$ is the time interval, and $\overline{Q O}$ and $\overline{\log (Q O)}$ are the long-term streamflow and the natural logarithm long-term streamflow.

\subsection{Ensemble Flood Forecast Performance}

The Relative Operative Characteristic (ROC) diagram is a graphic form to evaluate the ability of the forecast [55,56]. The construction of the ROC diagram is based on the $2 \times 2$ contingency tables for each probability threshold and presents the Hit Rate (HR) in relation to the False Alarm Rate (FAR) ordinate and abscissa, respectively, as follows:

$$
H R=\frac{a}{a+c}
$$

and:

$$
F A R=\frac{b}{b+d}
$$

where $a$ is the number of events that were observed and forecasted, $b$ is the number of events that were forecasted, but were not observed, $c$ is the number of events that were observed, but were not forecasted, and $d$ is the number of events that were neither observed, nor forecasted to occur. The best value in the ROC diagram is $H R=1$ and $F A R=0$ for all levels of probability. If $H R=F A R$, then the probability is equal to $50 \%$ for both, which provides meaningless information. The ROC diagram also allows determining the ROC skill score provided through the area calculated under the ROC curve.

Because the warning flood levels in small riverine towns of the basin have been poorly defined or not established at all, the statistics of performance were calculated for each 
sub-basin based on the threshold streamflow defined by the 90th percentile of the historical streamflow duration curves. This threshold indicates floods that cause disruptions in the local population with a recurrence time of about 1-2 $y$ and allows the comparison of the skill of the forecasts across different spatial and temporal scales. Warning level refers to the site-specific river level at which the river banks are overtopped and riverine housing begins to be flooded. Although it would be statistically more rigorous to choose a percentile of the annual maximum floods rather than the 90th percentile of the experimental probability of the flow duration curve, this would require at least $25 \mathrm{y}$ of data, which are not available for all sub-basins. In addition, the required period is much longer than the calibration and validation periods of the hydrological model (2000 to 2014) and the available ensemble forecasts (2007 to 2014). This is why we adopted this approach, which is analogous to the approximation used to assess ensemble weather forecasts [57].

\section{Results and Discussion}

\subsection{Hydrological Model Performance}

The calibration and validation of the MHD-INPE for 22 sub-basins of the Tocantins-Araguaia Basin using precipitation satellite estimates as the input of the model are shown in Table 1. The hydrological model showed good performances to simulate the streamflow and represent the seasonality of the streamflow, picks, and recession periods. In general, the NSE and $N S E_{\text {log }}$ showed good results for all sub-basins mainly for large basins with NSE and $N S E_{\log }$ of $0.868-0.957$ and $0.890-0.953$, respectively. The hydrological model was found less performance in two small sub-basins, Tesouro (SB03) and Jatobá (SB17), as well for the medium sub-basin, HPP Peixe Angical (SB14). As already noted by Falck et al. [38], the performance of the hydrological model is usually worse in headwater catchments due to the lack of data and model limitation. However, these results are acceptable for the purposes of this study according to Moriasi et al. [58].

Comparing the performances of the MHD-INPE model in the current study with the results of Falck et al. [38], where the same hydrological model was calibrated using interpolated rain gauge observations, this suggests that for small basins, the performance of the model for maximum discharges was better when the MHD-INPE was calibrated with observed data. For medium and large basins, the performances of the hydrological model were found superior when the model was calibrated with satellite data. This result could be due to the combination of scarce rain gauge data in headwater sub-basins (about one rain gauge for every $2500 \mathrm{~km}^{2}$ ) and uncertainties in satellite rainfall estimates in regions with a steeper topography [59].

\subsection{ROC Skill Score in Terms of Update}

The ROC skill score is shown in Figure 2 for 22 sub-basins for 15 lead times (one each $24 \mathrm{~h}$ ) as a function of the drainage area for streamflow with a probability level of 0.9 . To understand the importance of the update frequencies in flood operational prediction systems, we considered the update of the hydrological model every $1 \mathrm{~d}$, every $3 \mathrm{~d}$, every $7 \mathrm{~d}$, and $11 \mathrm{~d}$. Figure 2a shows the significant improvement of the ROC Skill Score (ROCSS) for a daily update when compared with a $3 \mathrm{~d}, 7 \mathrm{~d}$, and $11 \mathrm{~d}$ update (Figure $2 \mathrm{~b}-\mathrm{d}$ ). This figure shows the importance of daily updates to predict streamflow for all drainage areas. Concerning the $3 \mathrm{~d}, 7 \mathrm{~d}$, and $11 \mathrm{~d}$ updates, the results were very similar with a slight improvement for the $3 \mathrm{~d}$ update. However, the ROCSS decreased significantly for almost all lead times and sizes of sub-basins when compared with the daily update. 
Sub-basin Index

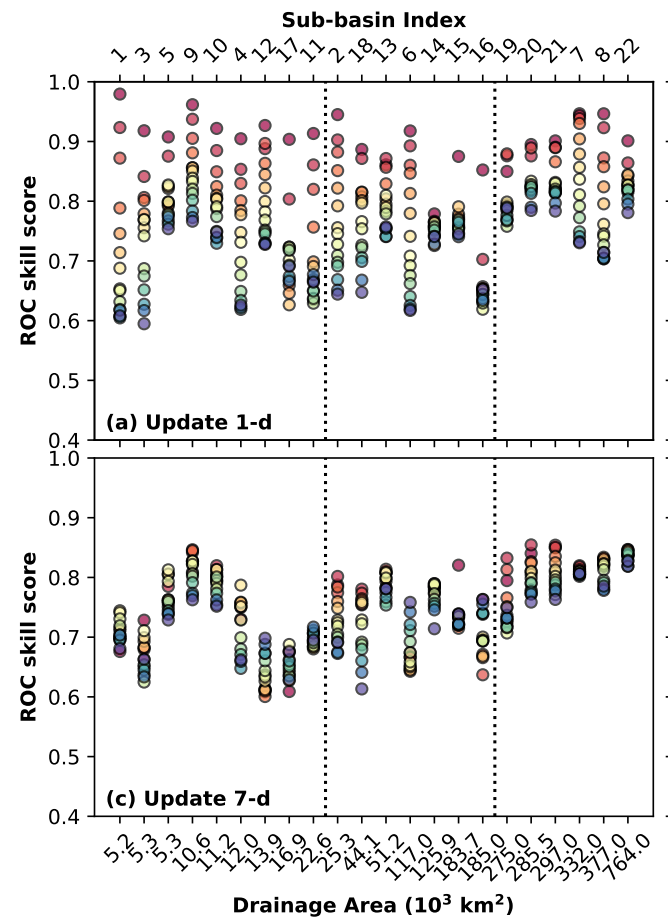

Sub-basin Index

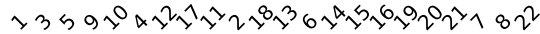

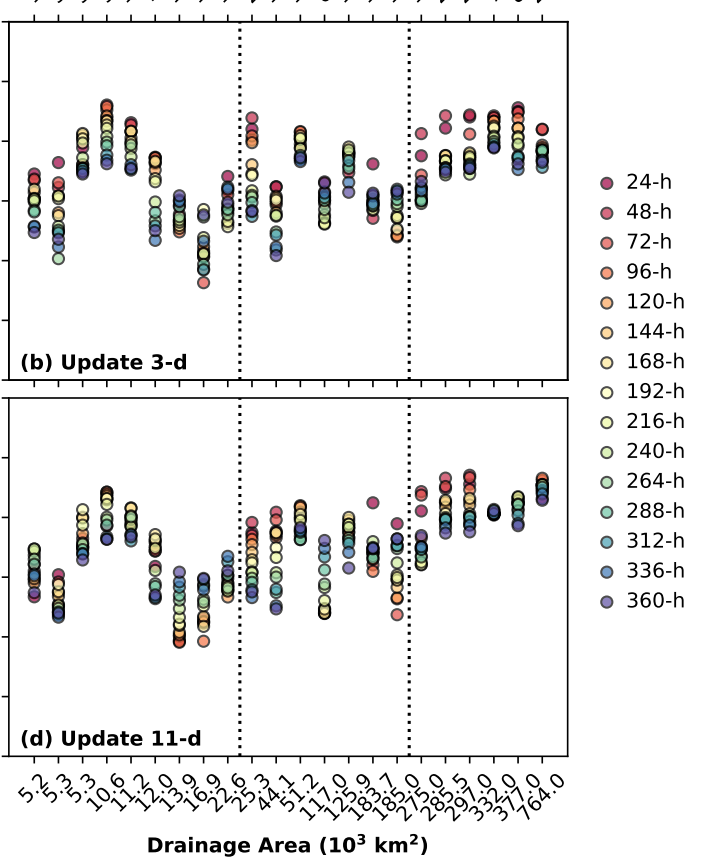

Figure 2. ROC skill score for 22 sub-basins of the Tocantins-Araguaia Basin for 15 lead times as a function of drainage area for streamflow with a probability level of 0.9. MHD-INPE update every (a) $1 \mathrm{~d}$, (b) $3 \mathrm{~d}$, (c) $7 \mathrm{~d}$, and (d) $11 \mathrm{~d}$ to the ECMWF ensemble. The vertical dotted lines divide the drainage area into small, medium, and large sub-basins.

In addition, Figure 3 exhibits the ROCSS as a function of forecast lead time for a $1 \mathrm{~d}$, $3 \mathrm{~d}, 7 \mathrm{~d}$, and $11 \mathrm{~d}$ update frequency for small, medium, and large sub-basins. The SB03 (Tesouro), SB05 (Travessão), and SB9 (Ceres) represent the small sub-basins (left column), SB13 (HPP Serra da Mesa), SB06 (Luiz Alves), and SB15 (HPP Lajeado) the medium subbasins (center column), and SB21 (Descarreto), SB07 (Conceição do Araguaia), and SB22 (HPP Tucuruí) the large sub-basins (right column). In general, the results showed better a ROCSS for a $1 \mathrm{~d}$ update mainly for the first lead times of the forecasting. For small subbasins, the ROCSS for a $1 \mathrm{~d}$ update was superior for the first lead times when compared with $3 \mathrm{~d}, 7 \mathrm{~d}$, and $11 \mathrm{~d}$, although there were differences among sub-basins. For instance, for SB03 (Tesouro), a $1 \mathrm{~d}$ update had better skill until a $264 \mathrm{~h}$ lead time forecast; while in the case of SB05 (Travessão) and SB9 (Ceres), the ROCSS for a $1 \mathrm{~d}$ update was better for the first $192 \mathrm{~h}$ and $168 \mathrm{~h}$ lead time forecasting, respectively. For a $3 \mathrm{~d}, 7 \mathrm{~d}$, and $11 \mathrm{~d}$ update frequency, the ROCSS decreased slightly. However, the results showed predictability for all update frequencies, but with significantly better results for a $1 \mathrm{~d}$ update with a better ROC skill score for the first lead time mainly for headwaters.

In the Araguaia River, in the western part of the basin, SB06 (Luiz Alves) and SB07 (Conceição do Araguaia) are characterized by large floodplain areas and longer hydrological memory, which explain why the ROCSS was less sensitive to the lead time of the forecasts. The update improved the skill of the forecasts for early time leads, until $216 \mathrm{~h}$. However, for later time steps, the updated simulations showed a lower ROCSS compared to the simulations without an update. This behavior is likely related to the update, which forces the model to simulate discharges close to the latest observations, by changing the model soil and water stores. This procedure might introduce space-time errors in the basin storage, affecting discharges at longer lead time forecasts. Errors in the basin store are long lasting in sub-basins with longer memory (large floodplains) such as SB06 and SB07. On the contrary, the basins of the east side of the Tocantins basins showed better results in the case of the update from all lead times, with the exception of SB22 HPP Tucuruí, where the ROCSS decreased slightly after a $72 \mathrm{~h}$ lead time, related to the signal of SB06 and SB07. 

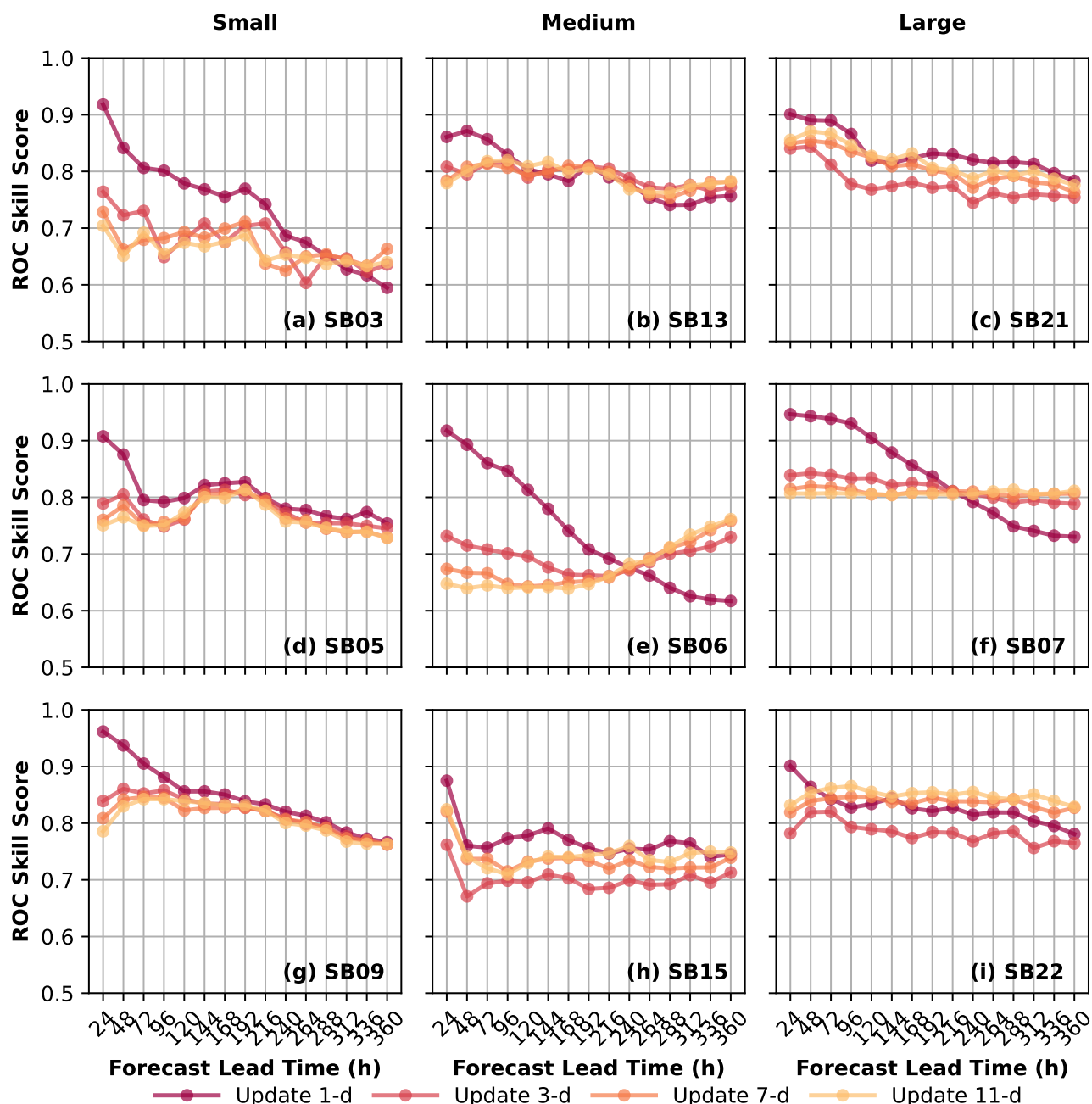

Figure 3. ROC skill score probabilistic streamflow forecast for the ECMWF ensemble model for different update frequencies and drainage areas: small sub-basins (left column), medium sub-basins (center column), and larger sub-basins (right column), for streamflow with a probability level of 0.9.

\subsection{ROC Skill Score in Terms of Latency}

Based on Figure 2a, it is clear that the accuracy of forecasts in flood operational prediction systems was improved for streamflow updates every $1 \mathrm{~d}$, particularly in headwater catchments where the response time is short and the floods are more destructive [60]. Therefore, we extended the analysis of a $1 \mathrm{~d}$ update for different latency periods, as shown in Figure 4. This figure exhibits the ROCSS for a streamflow update of $1 \mathrm{~d}$ as a function of the drainage area for $0 \mathrm{~h}, 24 \mathrm{~h}, 48 \mathrm{~h}$, and $72 \mathrm{~h}$ latencies to the ECMWF ensemble prediction. Figure 4a shows the optimal conditions of a flood operational prediction system with daily updates and no latency of the streamflow dataset to bring the model to the initial condition. It is clear that the latency time has large implications in terms of the skill of the forecasts, and it is an additional challenge for satellite altimeter missions aimed to attend to operational hydrological systems. In general, the ROC skill score decreased gradually with lead time, but no clear relationship was observed with the drainage area. There was a degradation in skill scores in the sub-basins SB14-SB16 and SB19-SB22, located downstream of HPP Serra da Mesa. As noted by Falck et al. [38], this is related to the operational rules of the dams that follow the daily variations of the power demand of the Brazilian Interconnected Grid, which depends not only on the seasonal pattern (dry and wet periods), but also on the increase in regional demand due to heat waves, regional droughts in other regions of the country, and grid impedance requirements, among several other factors. Figure $4 \mathrm{~b}-\mathrm{d}$ shows the update every $1 \mathrm{~d}$ and $24 \mathrm{~h}, 48 \mathrm{~h}$, and $72 \mathrm{~h}$ latencies, 
respectively. These results were very similar, but considerably inferior, compared to the results with no latency (Figure $4 a$ ).
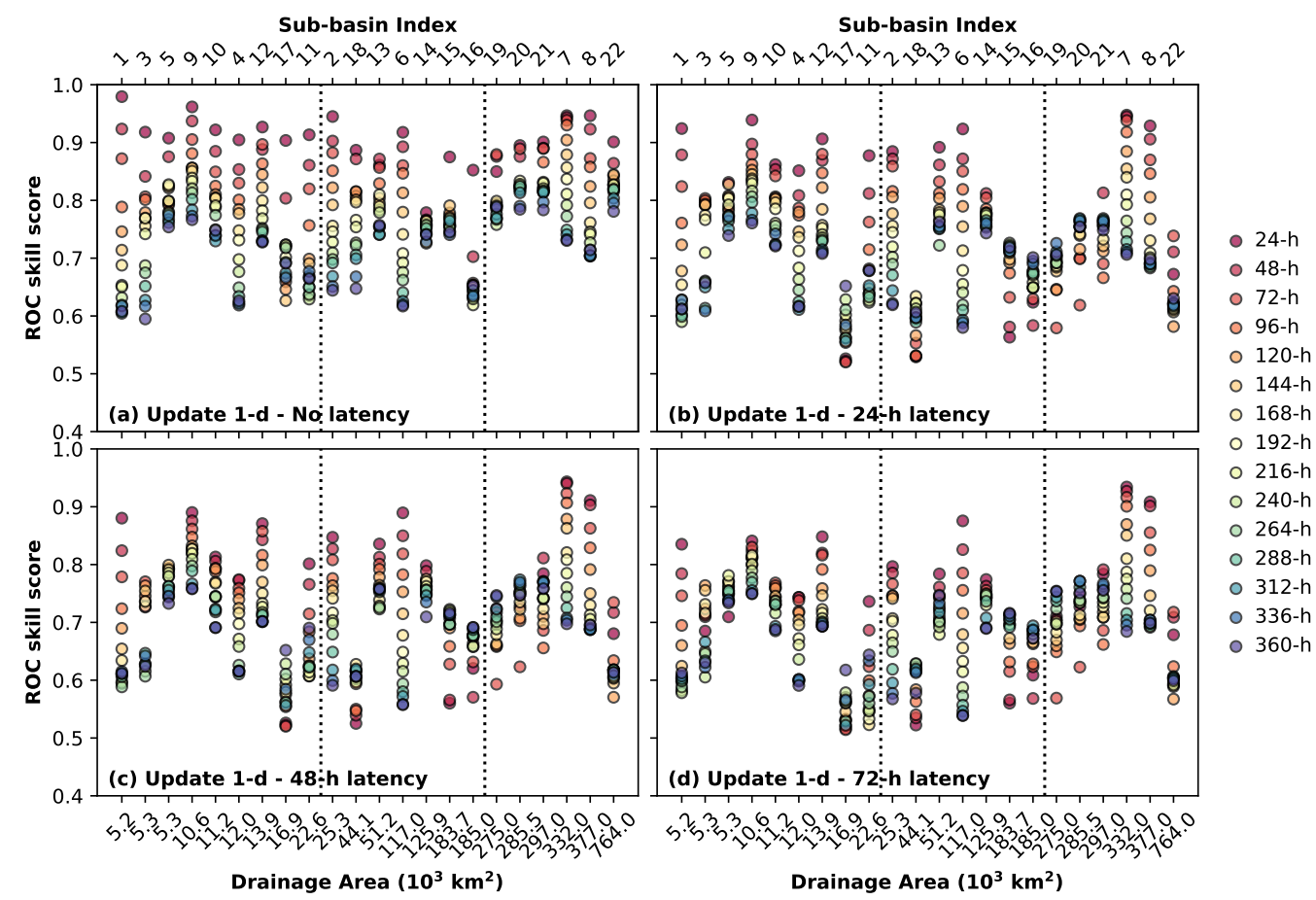

Figure 4. ROC skill score for 22 sub-basins of the Tocantins-Araguaia Basin for 15 lead times as a function of the drainage area for streamflow with a probability level of 0.9. MHD-INPE update every $1 \mathrm{~d}$ and (a) no latency, (b) $24 \mathrm{~h}$ latency, (c) $48 \mathrm{~h}$ latency, and (d) $72 \mathrm{~h}$ latency to the ECMWF ensemble. The vertical dotted lines divide the drainage area into small, medium, and large sub-basins.

Figure 5 shows the ROC skill score as a function of forecast lead time for a $1 \mathrm{~d}$ update frequency and $0 \mathrm{~h}, 24 \mathrm{~h}, 48 \mathrm{~h}$, and $72 \mathrm{~h}$ latencies for small, medium, and large sub-basins. In terms of latency, we observed that, in small sub-basins, the latency was important especially for the first lead times. For instance, the first lead time for small sub-basins SB03, SB05, and SB09 decreased the skill from 0.95 to 0.7 for $0 \mathrm{~h}$ to $72 \mathrm{~h}$ latencies (around 25\%). The ROCSS was degraded slightly with the lead time after $\sim 72 \mathrm{~h}$ of forecasting. The same occurred for medium basins, except for SB15 (HPP Lajeado), which is impacted by the sequence of reservoirs upstream. These results were propagated for the sub-basins downstream, affecting also large-scale basins such as SB21 (Descarreto) and SB22 (HPP Tucuruí).

In addition, regarding inflow discharge to reservoirs, it is worth mentioning that those estimations were based on the water balance of the reservoirs, thus neglecting the effects of the evaporation and infiltration of the reservoir lake. Besides the errors introduced by the water balance simplification, other sources of uncertainties were introduced by the sedimentation of the lake, which alters the stage-volume relationship with time.

Figures 6 and 7 (results for a 3 d update and various latencies) still show a gain in the analyzed ROCSS. In the case of $7 \mathrm{~d}$ and $11 \mathrm{~d}$ updates for $0 \mathrm{~h}, 24 \mathrm{~h}, 48 \mathrm{~h}$, and $72 \mathrm{~h}$ latencies (figures not shown), the latency time had no effect because the lead times overlapped. These results highlight the importance of the $1 \mathrm{~d}$ update and the latency. Even though data latency delays occurred, the daily update was extremely important. 

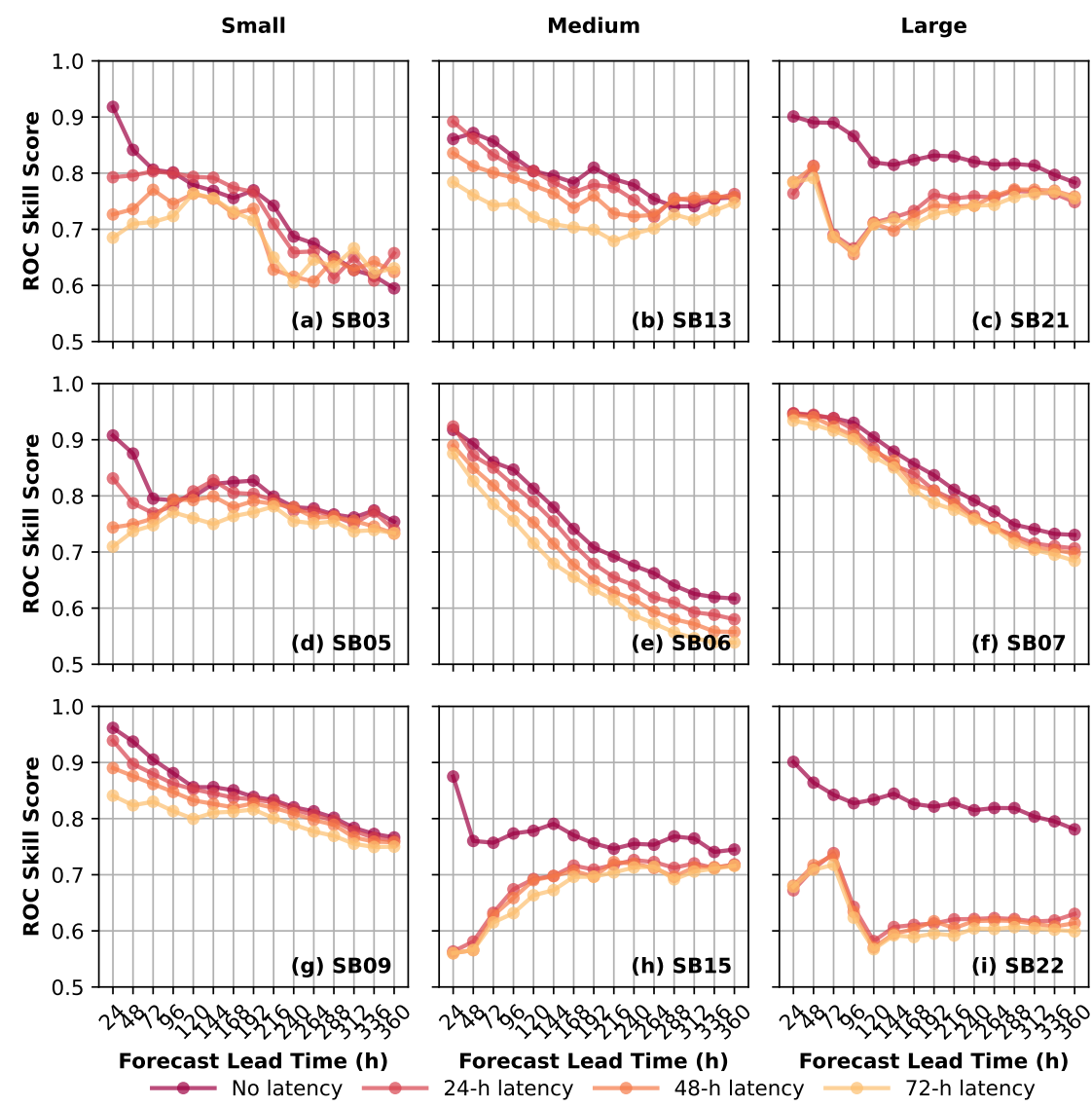

Figure 5. ROC skill score probabilistic streamflow forecast for the ECMWF ensemble model for a $1 \mathrm{~d}$ update and different latencies $(0 \mathrm{~h}, 24 \mathrm{~h}, 48 \mathrm{~h}$, and $72 \mathrm{~h}$ latencies) and drainage areas: small sub-basins (left column), medium sub-basins (center column), and larger sub-basins (right column), for streamflow with a probability level of 0.9 .
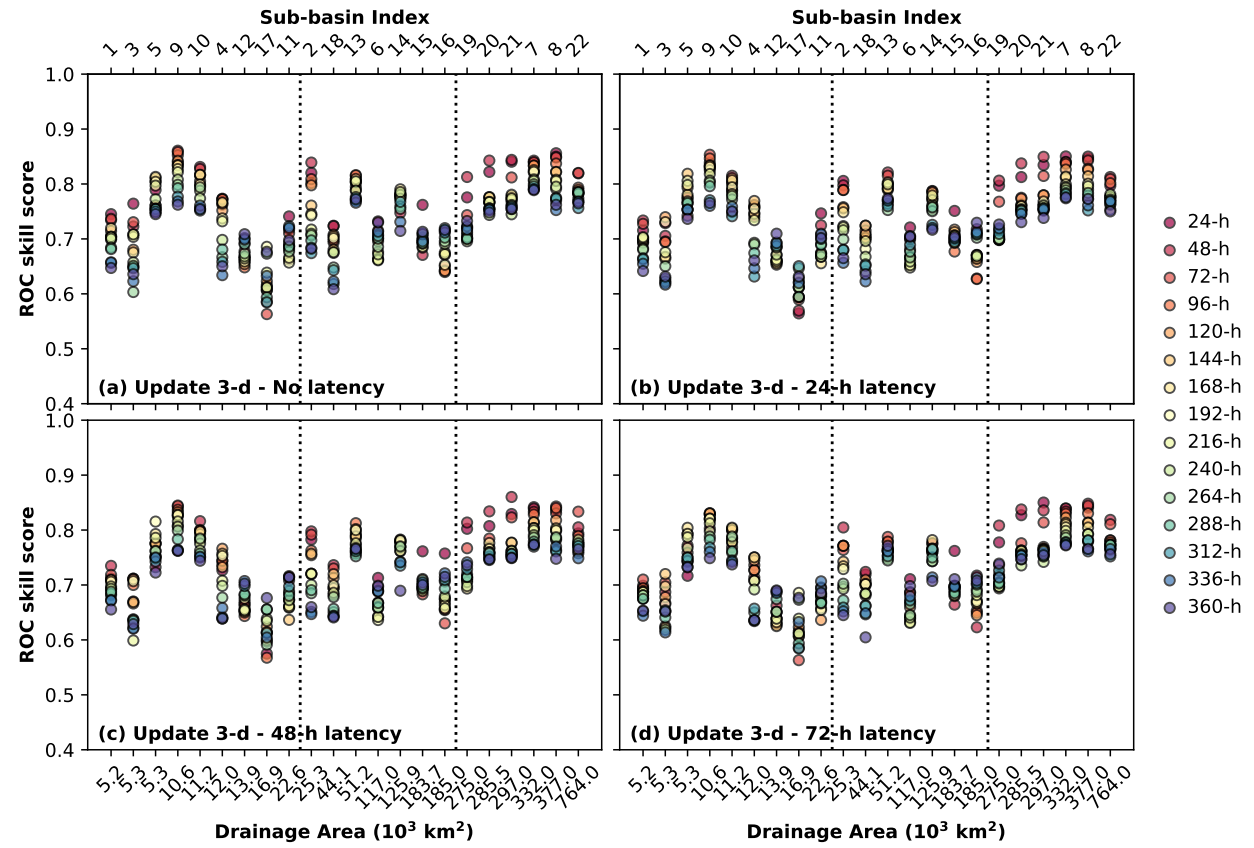

Figure 6. ROC skill score for 22 sub-basins of the Tocantins-Araguaia Basin for 15 lead times as a function of drainage area for streamflow with a probability level of 0.9. MHD-INPE update every $3 \mathrm{~d}$ and (a) no latency, (b) $24 \mathrm{~h}$ latency, (c) $48 \mathrm{~h}$ latency, and (d) $72 \mathrm{~h}$ latency to the ECMWF ensemble. The vertical dotted lines divide the drainage area into small, medium, and large sub-basins. 

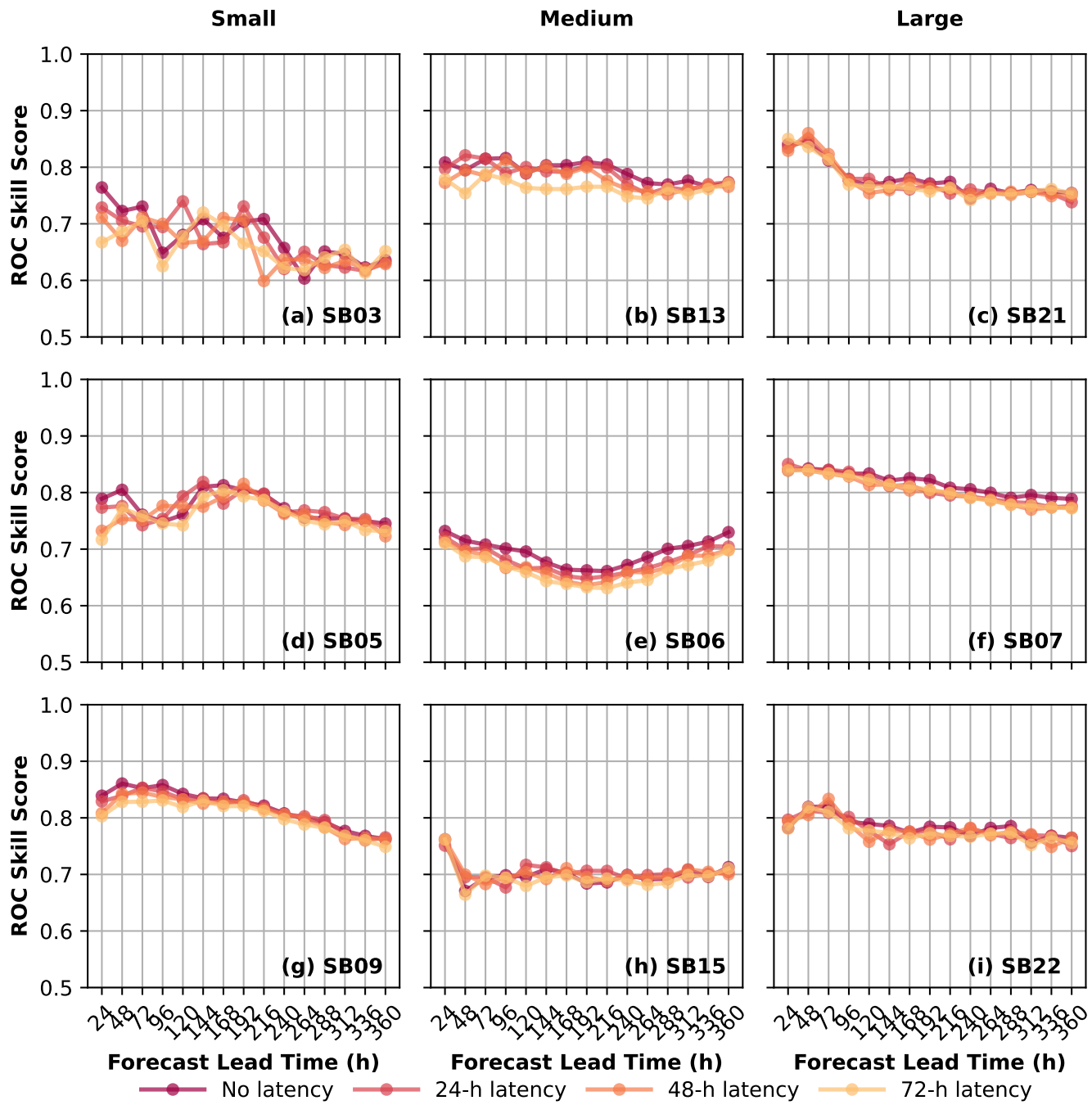

Figure 7. ROC skill score probabilistic streamflow forecast for the ECMWF ensemble model for a $3 \mathrm{~d}$ update and different latencies $(0 \mathrm{~h}, 24 \mathrm{~h}, 48 \mathrm{~h}$, and $72 \mathrm{~h}$ latencies) and drainage areas: small sub-basins (left column), medium sub-basins (center column), and larger sub-basins (right column), for streamflow with a probability level of 0.9 .

The ROC diagrams for small, medium, and large sub-basins are shown in Figures 8-10, respectively. The ROC diagram represents the hit rates and false alarm rates up to 15 lead times' forecasts and for a $1 \mathrm{~d}$ update frequency considering a probabilistic streamflow forecast with $0 \mathrm{~h}$ (no latency), $24 \mathrm{~h}$ latency, $48 \mathrm{~h}$ latency, and $72 \mathrm{~h}$ latency.

For small sub-basins (Figure 8) SB03, SB05, and SB09, the results showed that the dataset updated daily without latency presented the best performance especially for the first lead times' forecasts $(24 \mathrm{~h}, 48 \mathrm{~h}$, and $72 \mathrm{~h}$ forecasting). These results showed the importance of data latency for headwaters with fast hydrological responses. As the latency increased, the predictability performance decreased, especially for early lead times. For longer lead times, all latencies' experiments remained very similar to the no-latency ones. The results showed that for longer lead times in headwaters, the latencies did not have a major impact on the results. In the case of no latency for small sub-basins, the first lead times' forecasts had high hit rates (around 90\%) and low false alarm rates (between $0 \%$ and 30\%). For $24 \mathrm{~h}$ latency for short lead times, the results were slightly better than for $48 \mathrm{~h}$ and $72 \mathrm{~h}$ latencies, showing higher hit rates, but lower false alarm rates. This was something expected considering that the forecasts in headwater basins depend mostly on an accurate rainfall prediction, which is deteriorated not only because of increasing leading times, but also at finer spatial scales. In the case of medium and large sub-basins (Figures 9 and 10), 
the results were very similar for all latencies, especially for $0 \mathrm{~h}$ and $24 \mathrm{~h}$. For $48 \mathrm{~h}$ and $72 \mathrm{~h}$, the predictability decreased for the first lead times. In general, the results showed that for longer lead times for medium and larger sub-basins, the latencies had almost no effect. There were several reasons for this behavior. Firstly, the flood wave dynamics is more gradual for larger basins, which makes flood forecasts more predictable downstream. In addition, because the discharges of larger basins depend on rainfall falling on larger incremental contributed areas and on the propagation of flood waves from upslope subbasins, time and space errors in rainfall predictions in the incremental drainage area are spatially compensated. However, in the case of the dams HPP Lajeado (SB15), Descarreto (SB21), and HPP Tucuruí (SB22), the operating rules of which can change on a daily basis in response to the country's power demand, the hit rates dropped drastically by over $40 \%$, and the false alarm rates dropped between $10 \%$ and $20 \%$.
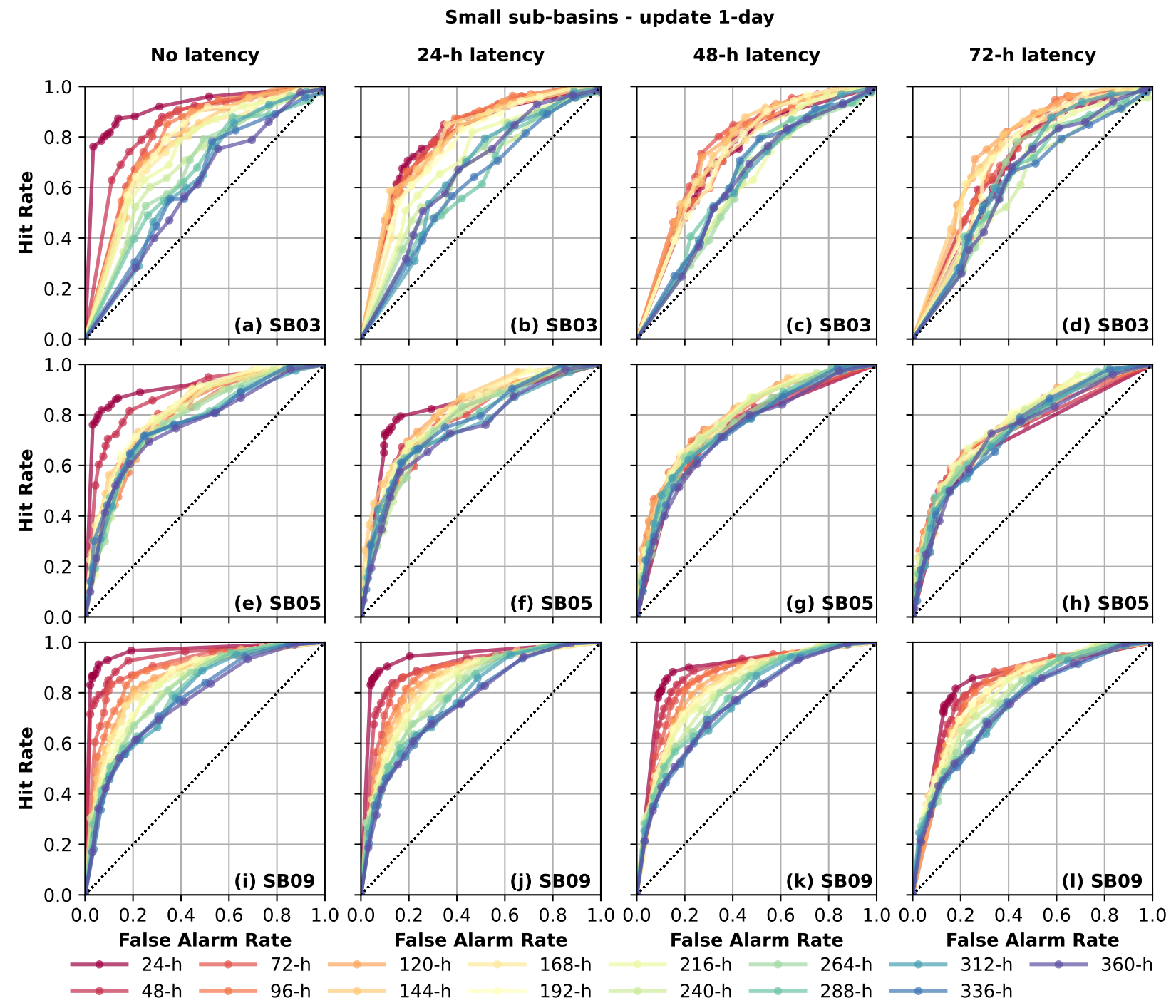

Figure 8. ROC diagrams of the probabilistic streamflow forecast for small sub-basins. MHD-INPE $1 \mathrm{~d}$ update for: no latency (left column), $24 \mathrm{~h}$ latency (center-left column), $48 \mathrm{~h}$ latency (center-right column), and $72 \mathrm{~h}$ latency (right column), for streamflow with a probability level of 0.9 . 


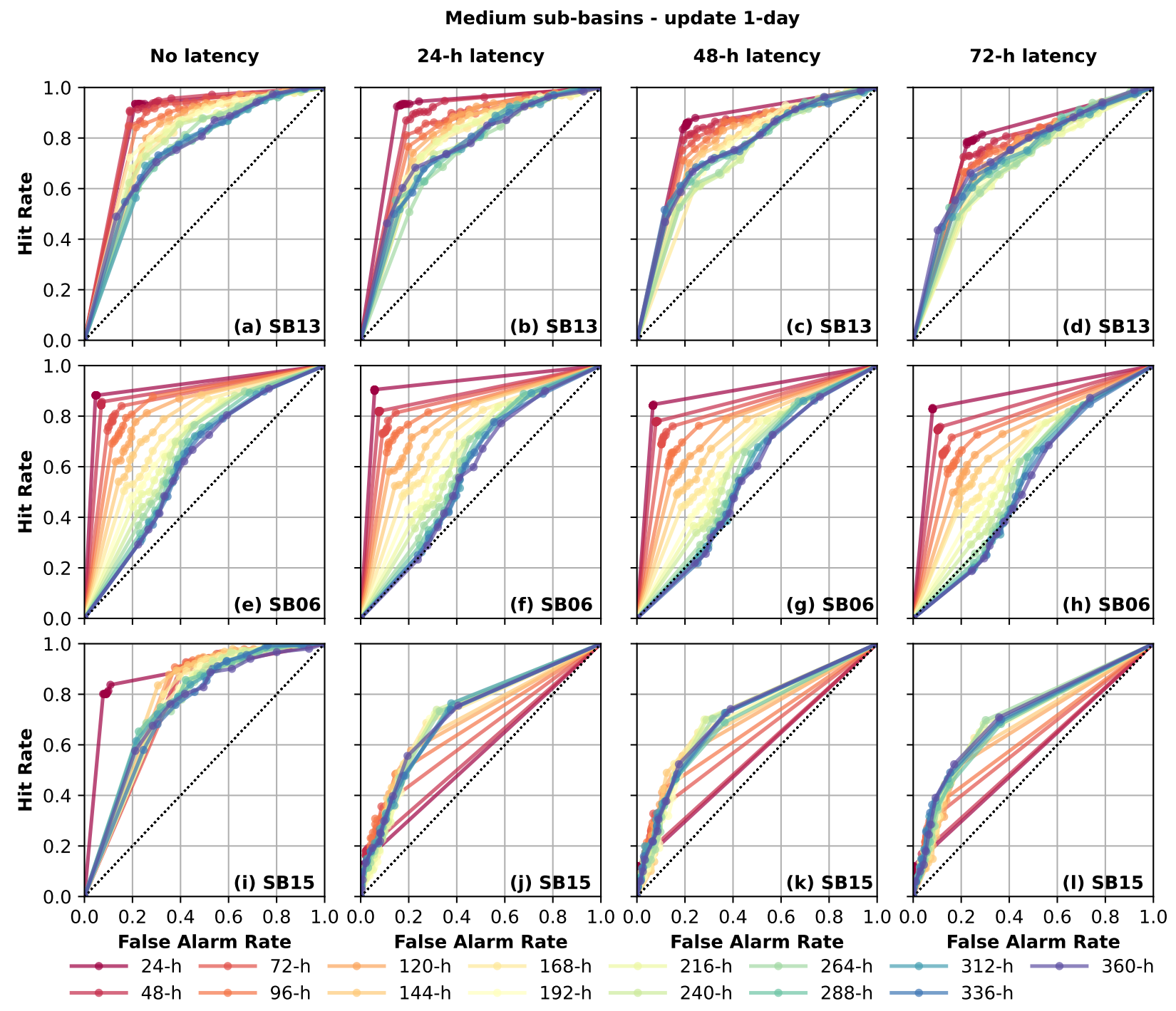

Figure 9. ROC diagrams of the probabilistic streamflow forecast for medium sub-basins. MHD-INPE $1 \mathrm{~d}$ update for: no latency (left column), $24 \mathrm{~h}$ latency (center-left column), $48 \mathrm{~h}$ latency (center-right column), and $72 \mathrm{~h}$ latency (right column), for streamflow with a probability level of 0.9 . 


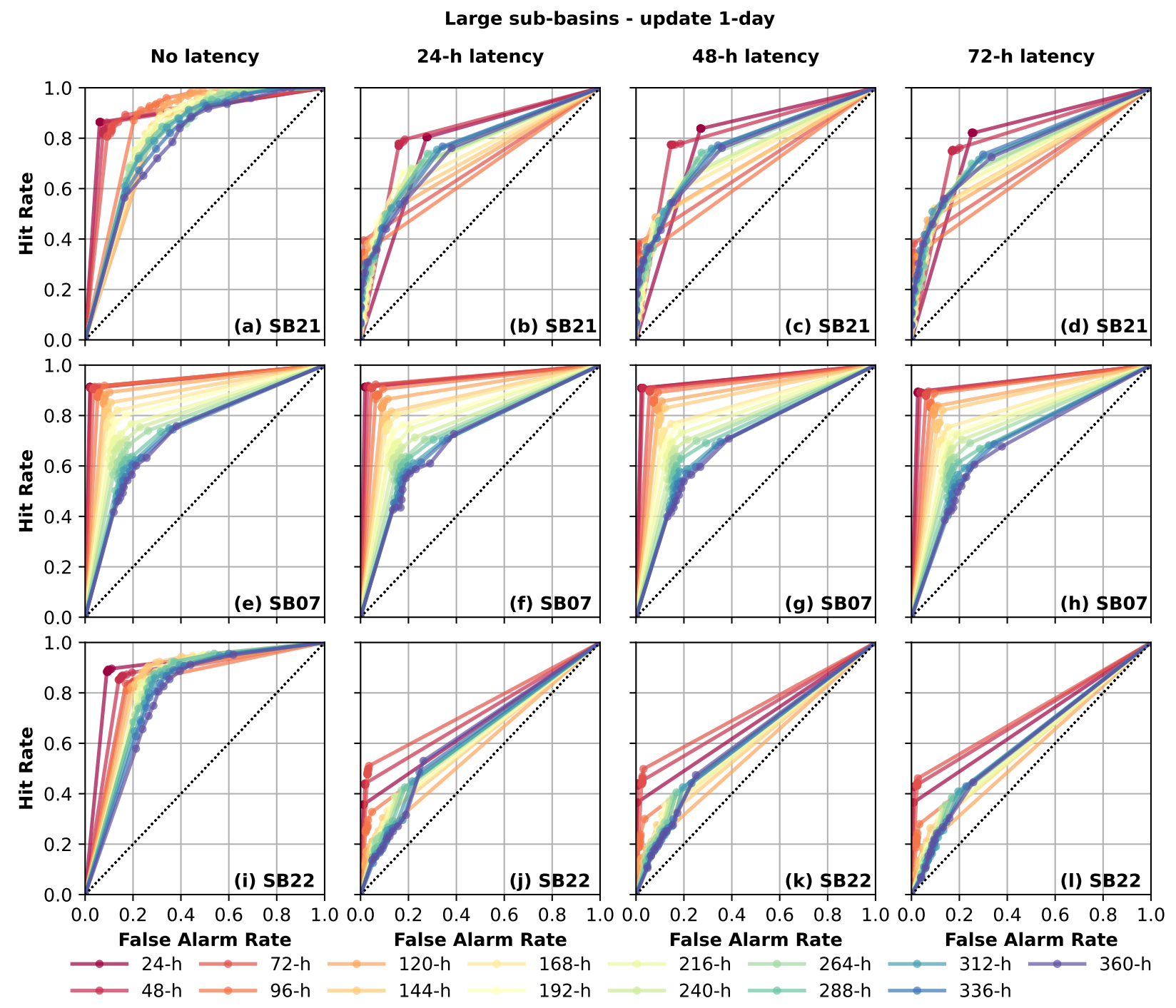

Figure 10. ROC diagrams of the probabilistic streamflow forecast for large sub-basins. MHD-INPE $1 \mathrm{~d}$ update for: no latency (left column), $24 \mathrm{~h}$ latency (center-left column), $48 \mathrm{~h}$ latency (center-right column), and $72 \mathrm{~h}$ latency (right column), for streamflow with a probability level of 0.9 .

\section{Summary and Conclusions}

To understand the potential applications offered by the upcoming altimeter missions for flood forecasting operational systems, we analyzed the results of several experiments considering the update frequencies of data for $1 \mathrm{~d}, 3 \mathrm{~d}, 7 \mathrm{~d}$, and $11 \mathrm{~d}$. For each update frequency, we analyzed the latency times $(0 \mathrm{~h}, 24 \mathrm{~h}, 48 \mathrm{~h}$, and $72 \mathrm{~h})$ as an initial condition of the hydrological model. The results were evaluated in terms of the ROC diagram, ROC skill score per drainage area, and per lead time of $15 \mathrm{~d}$ of streamflow forecasting.

Our results revealed that increasing the frequency of data collection and reducing the latency time (especially a $1 \mathrm{~d}$ update and low latency) had a strong effect mostly on steep headwater sub-basins, where the dynamics of the flood waves have the potential to cause not only more economic damage, but also human fatalities. In larger basins, although the increased frequency of data collection improved the accuracy of the forecasts, potential benefits are limited to the early days of the flood and less critical when compared to headwater sub-basins. Therefore, future satellite altimeter missions, to be more useful in flood forecasting systems, should emphasize the frequency of data collection (and vertical accuracy).

Therefore, our results support the initiative of the scientific community and CNES, which aim at developing the SMall Altimetry Satellites for Hydrology (SMASH) constella- 
tion, which will allow the monitoring of rivers (as narrow as $50 \mathrm{~m}$ wide) and lakes (with a minimum area of $100 \mathrm{~m}) \times 100 \mathrm{~m}$ with a daily revisit. In addition, our results emphasize that the products should be provided with a short latency time in order to make full use of the high temporal frequency of the measurements in the context of flood forecasting.

Considering the current status of the hydrological network in Brazil and that the real-time data are based on the mobile (cellular) network, which can be unreliable during extreme rainfall events, in particular in remote areas, it is clear that the use of satellite altimeter data can be crucial in many cases for flood mitigation actions.

Since this study used only a unique hydrological and weather forecast model, future studies should also explore the use of different numerical schemes (including more sophisticated assimilation schemes) and, more importantly, the effect of a higher spatial resolution on the quality of the forecasts. Furthermore, the Tocantins-Araguaia region is poorly monitored, and potential discharge estimations based on satellite altimeters with higher spatial coverage than the currently available gauging network are likely to have a positive effect on the forecasts. In parallel, the conversion of altimeter data into discharge and their validation over the Tocantins-Araguaia region require further investigation, including field surveys, to obtain additional rating curves or bathymetric data.

Author Contributions: A.F.: conceptualization, methodology, software, formal analysis, visualization, writing-original draft, writing — review and editing. J.T.: conceptualization, methodology, software, formal analysis, writing - review and editing. F.P.: conceptualization, methodology, formal analysis, writing - review and editing. All authors have read and agreed to the published version of the manuscript.

Funding: This work was supported by the Brazilian National Council for Scientific and Technological Development (CNPq). F.P. is partially funded by the Centre National d'Etude Spatiale (CNES) through the SWOT Science Team project SWOT for South America.

Acknowledgments: This work was based on The Interactive Grand Global Ensemble (TIGGE) data. TIGGE is an initiative of the World Weather Research Programme (WWRP).

Conflicts of Interest: The authors declare no conflict of interest.

\section{References}

1. Liu, Y.; Weerts, A.H.; Clark, M.; Hendricks Franssen, H.J.; Kumar, S.; Moradkhani, H.; Seo, D.J.; Schwanenberg, D.; Smith, P.; van Dijk, A.I.J.M.; et al. Advancing data assimilation in operational hydrologic forecasting: Progresses, challenges, and emerging opportunities. Hydrol. Earth Syst. Sci. 2012, 16, 3863-3887. [CrossRef]

2. Moradkhani, H.; DeChant, C.M.; Sorooshian, S. Evolution of ensemble data assimilation for uncertainty quantification using the particle filter-Markov chain Monte Carlo method. Water Resour. Res. 2012, 48, W12520. [CrossRef]

3. Nie, S.; Zhu, J.; Luo, Y. Simultaneous estimation of land surface scheme states and parameters using the ensemble Kalman filter: Identical twin experiments. Hydrol. Earth Syst. Sci. 2011, 15, 2437-2457. [CrossRef]

4. Ricci, S.; Piacentini, A.; Thual, O.; Le Pape, E.; Jonville, G. Correction of upstream flow and hydraulic state with data assimilation in the context of flood forecasting. Hydrol. Earth Syst. Sci. 2011, 15, 3555-3575. [CrossRef]

5. Thirel, G.; Martin, E.; Mahfouf, J.F.; Massart, S.; Ricci, S.; Regimbeau, F.; Habets, F. A past discharge assimilation system for ensemble streamflow forecasts over France-Part 2: Impact on the ensemble streamflow forecasts. Hydrol. Earth Syst. Sci. 2010, 14, 1639-1653. [CrossRef]

6. Vrugt, J.A.; ter Braak, C.J.; Diks, C.G.; Schoups, G. Hydrologic data assimilation using particle Markov chain Monte Carlo simulation: Theory, concepts and applications. Adv. Water Resour. 2013, 51, 457-478. [CrossRef]

7. Li, Y.; Ryu, D.; Western, A.W.; Wang, Q.; Robertson, D.E.; Crow, W.T. An integrated error parameter estimation and lag-aware data assimilation scheme for real-time flood forecasting. J. Hydrol. 2014, 519, 2722-2736. [CrossRef]

8. ANA. Evolução da Rede HidrometeorolóGica Nacional/Superintendência de Administração da Rede Hidrometeorológica; v. 1, n. 1; Agência Nacional de Águas: Brasília, Brasil, 2007.

9. de Assis Dias, M.C.; Saito, S.M.; dos Santos Alvalá, R.C.; Stenner, C.; Pinho, G.; Nobre, C.A.; de Souza Fonseca, M.R.; Santos, C.; Amadeu, P.; Silva, D.; et al. Estimation of exposed population to landslides and floods risk areas in Brazil, on an intra-urban scale. Int. J. Disaster Risk Reduct. 2018, 31, 449-459. [CrossRef]

10. Alvarez-Garreton, C.; Ryu, D.; Western, A.; Crow, W.; Robertson, D. The impacts of assimilating satellite soil moisture into a rainfall-runoff model in a semi-arid catchment. J. Hydrol. 2014, 519, 2763-2774. [CrossRef]

11. Crow, W.T.; Ryu, D. A new data assimilation approach for improving runoff prediction using remotely-sensed soil moisture retrievals. Hydrol. Earth Syst. Sci. 2009, 13, 1-16. [CrossRef] 
12. Dechant, C.; Moradkhani, H. Radiance data assimilation for operational snow and streamflow forecasting. Adv. Water Resour. 2011, 34, 351-364. [CrossRef]

13. Massari, C.; Brocca, L.; Barbetta, S.; Papathanasiou, C.; Mimikou, M.; Moramarco, T. Using globally available soil moisture indicators for flood modelling in Mediterranean catchments. Hydrol. Earth Syst. Sci. 2014, 18, 839-853. [CrossRef]

14. Wanders, N.; Karssenberg, D.; de Roo, A.; de Jong, S.M.; Bierkens, M.F.P. The suitability of remotely sensed soil moisture for improving operational flood forecasting. Hydrol. Earth Syst. Sci. 2014, 18, 2343-2357. [CrossRef]

15. Cretaux, J.; Frappart, F.; Papa, F.; Calmant, S.; Nielsen, K.; Benveniste, J. Satellite Altimetry over Oceans and Land Surfaces. In Hydrological Applications of Satellite Altimetry Rivers, Lakes, Man-Made Reservoirs, Inundated Areas; CRC Press: Boca Raton, FL, USA, 2017; pp. 459-504.

16. Santos da Silva, J.; Calmant, S.; Seyler, F.; Rotunno Filho, O.C.; Cochonneau, G.; Mansur, W.J. Water levels in the Amazon Basin derived from the ERS 2 and ENVISAT radar altimetry missions. Remote. Sens. Environ. 2010, 114, 2160-2181. [CrossRef]

17. Emery, C.M.; Paris, A.; Biancamaria, S.; Boone, A.; Calmant, S.; Garambois, P.A.; Santos da Silva, J. Large-scale hydrological model river storage and discharge correction using a satellite altimetry-based discharge product. Hydrol. Earth Syst. Sci. 2018, 22, 2135-2162. [CrossRef]

18. Emery, C.M.; Paris, A.; Biancamaria, S.; Boone, A.; Calmant, S.; Garambois, P.A.; Silva, J.S.D.; David, C.H. Discharge Estimation via Assimilation of Multisatellite-Based Discharge Products: Case Study Over the Amazon Basin. IEEE Geosci. Remote Sens. Lett. 2020, pp. 1-5. [CrossRef]

19. Paris, A.; Dias de Paiva, R.; Santos Da Silva, J.; Medeiros Moreira, D.; Calmant, S.; Garambois, P.A.; Collischonn, W.; Bonnet, M.P.; Seyler, F. Stage-discharge rating curves based on satellite altimetry and modeled discharge in the Amazon Basin. Water Resour. Res. 2016, 52, 3787-3814. [CrossRef]

20. Papa, F.; Biancamaria, S.; Lion, C.; Rossow, W.B. Uncertainties in mean river discharge estimates associated with satellite altimeters temporal sampling intervals: A case study for the annual peak flow in the context of the future SWOT hydrology mission. IEEE Geosci. Remote Sens. Lett. 2012, 4, 569-573. [CrossRef]

21. Papa, F.; Bala, S.K.; Pandey, R.K.; Durand, F.; Gopalakrishna, V.V.; Rahman, A.; Rossow, W.B. Ganga-Brahmaputra river discharge from Jason-2 radar altimetry: An update to the long-term satellite-derived estimates of continental freshwater forcing flux into the Bay of Bengal. J. Geophys. Res. Ocean. 2012, 117. [CrossRef]

22. Sikder, M.S.; Bonnema, M.; Emery, C.M.; David, C.H.; Lin, P.; Pan, M.; Biancamaria, S.; Gierach, M.M. A Synthetic Data Set Inspired by Satellite Altimetry and Impacts of Sampling on Global Spaceborne Discharge Characterization. Water Resour. Res. 2021, 57, e2020WR029035. [CrossRef]

23. Allen, G.H.; David, C.H.; Andreadis, K.M.; Hossain, F.; Famiglietti, J.S. Global Estimates of River Flow Wave Travel Times and Implications for Low-Latency Satellite Data. Geophys. Res. Lett. 2018, 45, 7551-7560. [CrossRef]

24. Biancamaria, S.; Lettenmaier, D.P.; Pavelsky, T.M. The SWOT Mission and Its Capabilities for Land Hydrology. Surv. Geophys. 2016, 37, 307-337. [CrossRef]

25. Blumstein, D.; Biancamaria, S.; Guérin, A.; Maisongrande, P. A potential constellation of small altimetry satellites dedicated to continental surface waters (SMASH mission). In Proceedings of the AGU Fall Meeting Abstracts, San Francisco, CA, USA, 9-13 December 2019 ; pp. H43N-2257, Volume 5805.

26. Valente, C.; Latrubesse, E.; Ferreira, L. Relationships among vegetation, geomorphology and hydrology in the Bananal Island tropical wetlands, Araguaia River Basin, Central Brazil. J. S. Am. Earth Sci. 2013, 46, 150-160. [CrossRef]

27. Seluchi, M.; Marengo, J.A. Tropical-Mid Latitude Exchange of Air Masses during Summer and Winter in South America: Climatic aspects and extreme events. Int. J. Climatol. 2000, 20, 1167-1190. [CrossRef]

28. Alvares, C.A.; Stape, J.L.; Sentelhas, P.C.; de Moraes Gonçalves, J.L.; Sparovek, G. Köppen’s climate classification map for Brazil. Meteorol. Z. 2013, 22, 711-728. [CrossRef]

29. Siqueira, J.L., Jr.; Tomasella, J.; Rodriguez, D.A. Impacts of future climatic and land cover changes on the hydrological regime of the Madeira River basin. Clim. Chang. 2015, 129, 117-129. [CrossRef]

30. Mohor, G.S.; Rodriguez, D.A.; Tomasella, J.; Júnior, J.L.S. Exploratory analyses for the assessment of climate change impacts on the energy production in an Amazon run-of-river hydropower plant. J. Hydrol. Reg. Stud. 2015, 4, 41-59. [CrossRef]

31. Rodriguez, D.A.; Tomasella, J. On the ability of large-scale hydrological models to simulate land use and land cover change impacts in Amazonian basins. Hydrol. Sci. J. 2016, 61, 1831-1846. [CrossRef]

32. Von Randow, R.C.S.; Rodriguez, D.A.; Tomasella, J.; Aguiar, A.P.D.; Kruijt, B.; Kabat, P. Response of the river discharge in the Tocantins River Basin, Brazil, to environmental changes and the associated effects on the energy potential. Reg. Environ. Chang. 2019, 19, 193-204. [CrossRef]

33. Michels-Brito, A.; Rodriguez, D.A.; Cruz Junior, W.L.; Nildo de Souza Vianna, J. The climate change potential effects on the run-of-river plant and the environmental and economic dimensions of sustainability. Renew. Sustain. Energy Rev. 2021, 147, 111238. [CrossRef]

34. Falck, A.S.; Maggioni, V.; Tomasella, J.; Vila, D.A.; Diniz, F.L.R. Propagation of satellite precipitation uncertainties through a distributed hydrologic model: A case study in the Tocantins-Araguaia basin in Brazil. J. Hydrol. 2015, 527, 943-957. [CrossRef]

35. Falck, A.S.; Maggioni, V.; Tomasella, J.; Diniz, F.L.R.; Mei, Y.; Beneti, C.A.; Herdies, D.L.; Neundorf, R.; Caram, R.O.; Rodriguez, D.A. Improving the use of ground-based radar rainfall data for monitoring and predicting floods in the Iguaçu river basin. $J$. Hydrol. 2018, 567, 626-636. [CrossRef] 
36. Casagrande, L.; Tomasella, J.; dos Santos Alvalá, R.C.; Bottino, M.J.; de Oliveira Caram, R. Early flood warning in the Itajaí-Açu River basin using numerical weather forecasting and hydrological modeling. Nat. Hazards 2017, 88, 741-757. [CrossRef]

37. Tomasella, J.; Sene Gonçalves, A.; Schneider Falck, A.; Oliveira Caram, R.; Rodrigues Diniz, F.; Rodriguez, D.; Rodrigues do Prado, M.; Negrão, A.; Sueiro Medeiros, G.; Chagas Siquiera, G. Probabilistic flood forecasting in the Doce Basin in Brazil: Effects of the basin scale and orientation and the spatial distribution of rainfall. J. Flood Risk Manag. 2019, 12, e12452. [CrossRef]

38. Falck, A.S.; Tomasella, J.; Diniz, F.L.; Maggioni, V. Applying a precipitation error model to numerical weather predictions for probabilistic flood forecasts. J. Hydrol. 2021, 598, 126374. [CrossRef]

39. Farr, T.G.; Rosen, P.A.; Caro, E.; Crippen, R.; Duren, R.; Hensley, S.; Kobrick, M.; Paller, M.; Rodriguez, E.; Roth, L.; et al. The Shuttle Radar Topography Mission. Rev. Geophys. 2007, 45, 33p. [CrossRef]

40. Rennó, C.D.; Nobre, A.D.; Cuartas, L.A.; Soares, J.V.; Hodnett, M.G.; Tomasella, J.; Waterloo, M.J. HAND, a new terrain descriptor using SRTM-DEM: Mapping terra-firme rainforest environments in Amazonia. Remote. Sens. Environ. 2008, 112, 3469-3481. doi: 10.1016/j.rse.2008.03.018. [CrossRef]

41. Cuartas, L.A.; Tomasella, J.; Nobre, A.D.; Nobre, C.A.; Hodnett, M.G.; Waterloo, M.J.; de Oliveira, S.M.; de Cássia von Randow, R.; Trancoso, R.; Ferreira, M. Distributed hydrological modeling of a micro-scale rainforest watershed in Amazonia: Model evaluation and advances in calibration using the new HAND terrain model. J. Hydrol. 2012, 462-463, 15-27. [CrossRef]

42. Santos, H.G.d.; Carvalho Junior, W.d.; Dart, R.d.O.; Aglio, M.L.D.; Sousa, J.S.d.; Pares, J.G.; Fontana, A.; Martins, A.L.d.S.; Oliveira, A.P.d.O. O Novo Mapa de Solos do Brasil : Legenda Atualizada; Embrapa Solos: Rio de janeiro, Brazil, 2011; 68p.

43. Souza, C.M.; Z. Shimbo, J.; Rosa, M.R.; Parente, L.L.; A. Alencar, A.; Rudorff, B.F.T.; Hasenack, H.; Matsumoto, M.; G. Ferreira, L.; Souza-Filho, P.W.M.; et al. Reconstructing Three Decades of Land Use and Land Cover Changes in Brazilian Biomes with Landsat Archive and Earth Engine. Remote. Sens. 2020, 12, 2735. [CrossRef]

44. Duan, Q.; Sorooshian, S.; Gupta, V. Effectivo and efficient global optimization for conceptual rainfall-runoff models. Water Resour. Res. 1992, 28, 1015-1031. [CrossRef]

45. Rozante, J.R.; Moreira, D.S.; de Goncalves, L.G.G.; Vila, D.A. Combining TRMM and Surface Observations of Precipitation: Technique and Validation over South America. Weather. Forecast. 2010, 25, 885-894. [CrossRef]

46. Rozante, J.R.; Gutierrez, E.R.; de Almeida Fernandes, A.; Vila, D.A. Performance of precipitation products obtained from combinations of satellite and surface observations. Int. J. Remote. Sens. 2020, 41, 7585-7604. [CrossRef]

47. WMO. Manual on Codes. Volumes I.2 \& 1.2 Volumes I.2 \& 1.2; Secretariat of the World Meteorological Organization: Geneva, Switzerland, 2007.

48. Rozante, J.R.; Vila, D.A.; Barboza Chiquetto, J.; Fernandes, A.D.A.; Souza Alvim, D. Evaluation of TRMM/GPM Blended Daily Products over Brazil. Remote. Sens. 2018, 10, 882. [CrossRef]

49. Bougeault, P.; Toth, Z.; Bishop, C.; Brown, B.; Burridge, D.; Chen, D.H.; Ebert, B.; Fuentes, M.; Hamill, T.M.; Mylne, K.; et al. The THORPEX Interactive Grand Global Ensemble. Bull. Am. Meteorol. Soc. 2010, 91, 1059-1072. [CrossRef]

50. Swinbank, R.; Kyouda, M.; Buchanan, P.; Froude, L.; Hamill, T.M.; Hewson, T.D.; Keller, J.H.; Matsueda, M.; Methven, J.; Pappenberger, F.; et al. The TIGGE Project and Its Achievements. Bull. Am. Meteorol. Soc. 2016, 97, 49-67. [CrossRef]

51. ECMWF. Part V: Ensemble Prediction System. In IFS Documentation CY47R1; Number 5 in IFS Documentation; ECMWF: Reading, UK , 2020; Chapter 5, p. 23.

52. Buizza, R.; Bidlot, J.R.; Wedi, N.; Fuentes, M.; Hamrud, M.; Holt, G.; Vitart, F. The new ECMWF VAREPS (Variable Resolution Ensemble Prediction System). Q. J. R. Meteorol. Soc. 2007, 133, 681-695. [CrossRef]

53. Alfieri, L.; Pappenberger, F.; Wetterhall, F.; Haiden, T.; Richardson, D.; Salamon, P. Evaluation of ensemble streamflow predictions in Europe. J. Hydrol. 2014, 517, 913-922. [CrossRef]

54. Wöhling, T.; Lennartz, F.; Zappa, M. Technical Note: Updating procedure for flood forecasting with conceptual HBV-type models. Hydrol. Earth Syst. Sci. 2006, 10, 783-788. [CrossRef]

55. Wilks, D.S. Statistical Methods in the Atmospheric Sciences, 2nd ed.; International Geophysics, Elsevier Science: Amsterdam, The Netherlands, 2005.

56. Fawcett, T. An introduction to ROC analysis. Pattern Recognit. Lett. 2006, 27, 861-874. [CrossRef]

57. Ridolfi, E.; Kumar, H.; Bárdossy, A. A methodology to estimate flow duration curves at partially ungauged basins. Hydrol. Earth Syst. Sci. 2020, 24, 2043-2060. [CrossRef]

58. Moriasi, D.N.; Arnold, J.G.; Van Liew, M.W.; Bingner, R.L.; Harmel, R.D.; Veith, T.L. Model Evaluation Guidelines for Systematic Quantification of Accuracy in Watershed Simulations. Trans. ASABE 2007, 50, 885-900. [CrossRef]

59. Mei, Y.; Anagnostou, E.N.; Nikolopoulos, E.I.; Borga, M. Error Analysis of Satellite Precipitation Products in Mountainous Basins. J. Hydrometeorol. 2014, 15, 1778-1793. [CrossRef]

60. Bryndal, T.; Franczak, P.; Kroczak, R.; Cabaj, W.; Kołodziej, A. The impact of extreme rainfall and flash floods on the flood risk management process and geomorphological changes in small Carpathian catchments: A case study of the Kasiniczanka river (Outer Carpathians, Poland). Nat. Hazards 2017, 88, 95-120. [CrossRef] 